\title{
Impairment and recovery of left motor function in patients with right hemiplegia
}

\author{
Ph Marque, A Felez, M Puel, J F Demonet, B Guiraud-Chaumeil, C F Roques, F Chollet
}

\begin{abstract}
Objective-To assess the motor function of the left, supposedly unaffected, limbs of patients with an acute right vascular hemiplegia.

Methods-Fifteen patients with an acute vascular right hemiplegia and 16 matched healthy controls were studied. Motor function of the left limbs of each patient was evaluated on days 20 and 90 after their stroke using four validated tools (hand dynamometer, isokinetic dynamometer, finger tapping, and nine hole peg test).

Results-There was a significant impairment of motor function of the left limbs of patients at day 20 compared with controls. The impairment had recovered almost completely at day 90 after the stroke.

Conclusion-These results show the bilateral cerebral representation of the human motor system and suggest the participation of ipsilateral motor pathways in recovery after a stroke.
\end{abstract}

$(\mathcal{F}$ Neurol Neurosurg Psychiatry 1997;62:77-81)

Keywords: motor function; stroke; hemiplegia

The Swedish neuroanatomist Brodal ${ }^{1}$ was the first to describe a right motor impairment after his own acute left sided hemiplegia. He particularly mentioned a deficit affecting his handwriting; irregularities in letters, lines, and intervals were noticed. Several years later, other authors, ${ }^{23}$ using isometric testing, reported similar findings and showed the presence of a discrete but actual ipsilateral deficit in hemiplegic patients.

These clinical findings firstly suggest that, in humans, despite its high degree of lateralisation, the motor system remains bilateraly distributed in the brain and may be bilaterally involved in the execution of motor tasks. Bilateral activation of motor cortices during the performance of unilateral motor tasks in normal subjects has been documented. Colebatch and Gandevia ${ }^{4}$ and Sabatini et al, ${ }^{5}$ using PET and SPECT respectively, failed to detect any ipsilateral activation in normal subjects executing unilateral motor tasks. Concurently, Shibasaki et al showed that the performance of complex motor tasks was accompanied by a bilateral activation of motor cortices. ${ }^{6}$ Studies with PET emphasised the influence of the healthy hemisphere in the process of recovery after a stroke. ${ }^{78}$ They suggest the existence of a functional ipsilateral motor pathway. ${ }^{9}$

Secondly, the clinical finding of an ipsilateral motor deficit in patients with hemiplegic stroke raises the question of the participation of ipsilateral motor pathways in the processes of recovery after a stroke.

This clinical study aimed prospectively: (1) to assess the presence of a left motor deficit in patients with acute right hemiplegia using a set of complementary tests including isokinetic testing of force; (2) to characterise the type and topography of the deficit; and (3) to describe its time course during the first three months after the stroke.

\section{Subjects and methods PATIENTS AND CONTROLS \\ Patients}

Fiftreen of 24 consecutive patients (10 men, five women; mean age 65.6 (SD 14.3)) referred to the neurology department for acute right vascular hemiplegia were included. They were selected according to the presence of the following criteria:

- They all had a first right sided motor deficit of abrupt onset (affecting arm and leg) corresponding to a single vascular left hemispheric lesion. All lesions were unique and were confirmed by CT. Twelve were ischaemic (six striatocapsular infarctions, five infarctions of the superficial sylvian artery territory, one large sylvian infarction involving deep and superficial sylvian artery territory) and three were haemorrhagic (basal ganglia haematomas).

- They were able to perform the tests used in this study

- They were free of other disease.

All of them were right handed. Ten showed mild to moderate aphasic symptoms, but at the time of the study, their language was good enough to allow the performance of the motor tests in apropriate conditions. A mild right sensory deficit was present in nine patients. None of them had any orthopaedic or cardiac symptoms which could interfere with the performance of isokinetic motor tests.

The right motor deficit was assessed using the combination of three validated indexes: the trunk control test, a motor function index, and the Ashworth scale. ${ }^{10-13}$ The data were rescaled so that the maximum score did not exceed 100.

Nine of the 24 patients patients could not be included in the study and were rejected: 
three of them died before the 50th day; two patients were unable to participate because of severe aphasic symptoms; two others had another disease which could have interfered with the results of the tests; and two patients refused to participate in the study.

\section{Controls}

A control group of 16 healthy right handed sedentary subjects (mean age $65(15 \cdot 7)$ ) (10 men, six women) matched for age and sex and also height $(\mathrm{H})$, weight $(\mathrm{W})$, and body mass index $\left(\mathrm{BMI}=\mathrm{H} / \mathrm{W}^{2}\right)$, was selected, as human strength partly depends on anthropometric data, particularly for weight bearing muscles.

MOTOR FUNCTION OF LEFT LIMBS

We studied the motor function on the left side of the patients and of their controls with four validated tests.

\section{Hand dynamometer}

The purpose of this test was to measure the strength or intensity of the voluntary movements of the hand..$^{14-15} \mathrm{We}$ used dynamometer model 68810, Vitalsigns TM, Japan. The length of the dynamometer stirrup was adjusted to the size of the subject's hand. The subjects held the upper part of the dynamometer in the palm of their left hand, their arm down at the side and away from the body. They were asked to squeeze the stirrup with their fingers as hard as possible. The grip strength was recorded in $\mathrm{kg}$. Three consecutive tests with five minutes rest were performed. We used the highest of the three trials.

\section{Isokinetic dynamometer}

The isokinetic dynamometer ${ }^{16}$ aims at recording the joint moment of force when the contracting muscles cause the joint to rotate at a predetermined angular rate. Such contractions approximate to isokinetic conditions within the muscle and can be used to determine the forcevelocity characteristics in vivo. Hence it allows assessment of phasic strength. At low speed, the method correlates satisfactorily with isometric measurements and its reproducibility has been found to be better. ${ }^{17}$ Very strict conditions are necessary to guarantee good reproductibility ${ }^{18}$ - namely, standardised position, correction of gravity error, and training period. This method was validated with young and old subjects ${ }^{19}$ and with patients with rheumatologi$\mathrm{cal}^{20}$ and neurological diseases. ${ }^{21}$

We used an isokinetic dynamometer Cybex 600 (Cybex division, Lumex Inc, Ronkonkoma, New York, USA). A training period of four runs with five minutes rest was performed before the testing set. The testing procedure included four flexions and four extensions with full range motion. Because of the risks of muscles and tendons tearing at low speed, particularly with old people, we used the usual medium speed ${ }^{22}$ for each joint. Flexion and extension of hip, wrist, and elbow and eversion and inversion of the ankle were tested in each patient and control. Isokinetic testing was performed at $60 \% \mathrm{~s}$ for the hip and ankle, at $90 \%$ for the elbow, and at $120 \%$ s for the wrist.
The shoulder and knee were not tested. We did not test the shoulder because orthopaedic dysfunction is often present in that age class. We found the knee difficult to test with this technique as it requires the patients to be sitting and their axial musculature to participate.

We have used the usual standardised positioning of the subject and a full description is given by Davis ${ }^{22}$ and the user's guide of Cybex 6000 (Cybex Division of LUMEX, Ronkonkoma, New York, USA)

The subject was lying down on the Cybex table and was stabilised by a pelvic belt and a torso belt for isokinetic testing of the hip, ankle, and elbow. For the wrist the subject was seated and stabilised on the chair by a pelvic belt and a torso belt. Joints and segments not involved in the measurements were fastened by straps.

The axis of rotation of the dynamometer was placed in front of the joint axis. An adjustable arm with strapped thigh pad (hip), or hand grips (elbow and wrist), or footstrap (ankle) allowed the tested segment of the left limb to rotate the dynamometer axis. Full range of motion was tested except for the hip, in which range limitations reduced the motion from $-10^{\circ}$ extension to $+90^{\circ}$ flexion to avoid low back pain. The computer procedure allowed the impact of gravity to be measured and gravity error to be corrected at the same time. For all these joints the value recorded was the maximum moment or peak torque measured in Newton meters $(\mathrm{Nm})$.

\section{Finger tapping}

The purpose of this test ${ }^{14}$ was to measure the motor speed of the index finger. ${ }^{15}$ The subject was asked to tap for 10 seconds as quickly as possible with the left index finger on a computer key (MacIntosh LCII, Apple Computer Inc, Cupertino, CA, USA). The subject's left hand was placed palm down, index finger on the key. The investigator was careful that the subject moved only the index finger. The number of taps was automatically recorded by the computer. Five consecutive trials were recorded for each subject. When the results were too variable from one trial to another (more than a five point range from fastest to slowest) additional trials were run and the scores of the deviant trials were discarded. A maximum of 10 trials was allowed. A period of five minutes rest was given after each trial. We considered the mean of the best five trials.

\section{Nine hole peg test}

The purpose of this test was to measure finger and hand dexterity or accuracy. ${ }^{10}$ The subject was asked to place nine pegs in nine holes and to remove them with the left hand as quickly as possible. We used nine wooden dowels of 9 $\mathrm{mm}$ diameter and $32 \mathrm{~mm}$ length. The board was a wooden base with nine holes $(10 \mathrm{~mm}$ diameter, $15 \mathrm{~mm}$ deep) $15 \mathrm{~mm}$ apart in three rows of three holes and with a tray $100 \mathrm{~mm}$ square and $100 \mathrm{~mm}$ deep to hold the pegs. The computer recorded the time neccessary to perform the test. Five trials with five minutes rest were recorded. We used the mean of the five trials. 
CHRONOLOGY AND STATISTICS

The complete procedure lasted about three hours including the resting periods. The patients were evaluated twice: the first measurement was performed 20.8 (SD 12) days after the onset of the stroke, the second was performed 90.3 (SD 15) days after the onset of the stroke.

Non-parametric tests were used. The results at day 20 and day 90 were compared by the Wilcoxon signed rank test. The comparison between patients and controls was performed with the Mann-Whitney $U$ test.

\section{Results (table)}

HAND DYNAMOMETER

Our patients showed a significantly diminished hand grip at day 20 compared with controls. The hand grip of the patients improved significantly between days 20 and 90 .

\section{ISOKINETIC TESTING}

Hip

We found a significant decrease of the peak torque of the flexion and of the extension of our patients' hips at day 20 compared with the controls. The peak torque of the hip increased significantly between the 20th day and the 90th day. Hip extension peak torque remained significantly impaired at day 90 in patients compared with their control group.

\section{Ankle}

Inversion of the ankle in the patients showed a significant decrease of peak torque at day 20 compared with controls. Peak torque increased significantly in our patients at day 90 . Despite a decreasing trend, the differences recorded for ankle eversion were not significant.

Elbow

Despite similar trends to the hip and ankle, the deficit recorded on elbow testing between patients and their controls did not reach significance.

Wrist

Isokinetic testing of wrist flexion and exten- sion showed a significant decrease of peak torque in our patients at day 20 compared with their controls. This peak torque had significantly increased at day 90 in the patient group.

\section{FINGER TAPPING}

No difference in finger tapping performance was detected between patients and controls either at day 20 or at day 90 .

NINE HOLE PEG TEST

The nine hole peg test showed a significant difference between patients on day 20 and controls and between patients at day 20 and at day 90 . Performance on the nine hole peg test remained significantly impaired in patients on day 90 .

\section{Discussion}

This clinical study showed that in patients with an acute vascular right hemiplegia, a motor deficit could be seen on their supposedly unaffected left side and this motor deficit recovered during the first weeks after the stroke. Force (hand grip, isokinetic movements) and dexterity (nine hole peg test) were mainly concerned whereas repetitive movements (finger tapping) were spared. Recovery at day 90 was not complete as the nine hole peg test test and hip extension peak torque were still significantly different from the controls.

We think that the left sided motor deficit is valid and does not correspond to an artefact. Our data for patients did present a wide range of values with wide standard deviations but this was also the case in our control population and corresponds to the fact that the results depend on age, sex, and anthropometric data. It is also our opinion that the motor tasks were performed in appropriate conditions and that the patients produced a maximum effort. All the patients were able to understand and to perform the tasks. The repetition of trials and the reproducible shape of the four curves recorded for each set of isokinetic movements increases our confidence in the data. Moreover, this left sided deficit does not seem to be related to bed rest as it is known that these prevail on weight bearing muscles and it

Left motor function of patients and controls: measurements and statistical comparisons

\begin{tabular}{|c|c|c|c|c|c|c|}
\hline & \multicolumn{3}{|l|}{ Patients } & \multicolumn{3}{|l|}{ Controls } \\
\hline & $\begin{array}{l}\text { Day } 20 \\
\text { Mean }(S D)\end{array}$ & $\begin{array}{l}\text { Day } 90 \\
\text { Mean (SD) }\end{array}$ & $\begin{array}{l}P \text { value }< \\
\text { Day 20/day } 90\end{array}$ & Mean $(S D)$ & Day $20 / C$ & $\begin{array}{l}\text { alue }< \\
\text { Day } 90 / C\end{array}$ \\
\hline $\begin{array}{l}\text { Hand dynamometer } \\
\text { Hip: }\end{array}$ & $16 \cdot 3(12 \cdot 6)$ & $21 \cdot 6(13 \cdot 6)$ & 0.01 & $27 \cdot 2(11 \cdot 2)$ & 0.05 & NS \\
\hline $\begin{array}{l}\text { PT flex } \\
\text { PT ext } \\
\text { Ankle: }\end{array}$ & $\begin{array}{l}50 \cdot 4(24 \cdot 7) \\
35 \cdot 2(32 \cdot 3)\end{array}$ & $\begin{array}{l}68 \cdot 1(25 \cdot 2) \\
63 \cdot 4(41 \cdot 3)\end{array}$ & $\begin{array}{l}0.01 \\
0.01\end{array}$ & $\begin{array}{r}93 \cdot 8(41 \cdot 8) \\
110.9(56)\end{array}$ & $\begin{array}{l}0.01 \\
0.001\end{array}$ & $\begin{array}{l}\text { NS } \\
0.05\end{array}$ \\
\hline $\begin{array}{l}\text { Ankle: } \\
\text { PT inv } \\
\text { PT ever } \\
\text { Elbow }\end{array}$ & $\begin{array}{l}8.7(7.6) \\
9.9(6.4)\end{array}$ & $\begin{array}{l}12 \cdot 1(7 \cdot 6) \\
11 \cdot 9(12 \cdot 4)\end{array}$ & $\begin{array}{l}0.01 \\
\text { NS }\end{array}$ & $\begin{array}{l}15 \cdot 1(8 \cdot 8) \\
12 \cdot 4(8 \cdot 1)\end{array}$ & $\begin{array}{l}0.05 \\
\text { NS }\end{array}$ & $\begin{array}{l}\text { NS } \\
\text { NS }\end{array}$ \\
\hline $\begin{array}{l}\text { PT flex } \\
\text { PT ext } \\
\text { Wrist }\end{array}$ & $\begin{array}{l}21 \cdot 7(14 \cdot 2) \\
26.5(17 \cdot 6)\end{array}$ & $\begin{array}{l}26 \cdot 1(13 \cdot 3) \\
32 \cdot 3(15 \cdot 2)\end{array}$ & $\begin{array}{l}\text { NS } \\
0.05\end{array}$ & $\begin{array}{l}29.9(10 \cdot 3) \\
34 \cdot 4(12 \cdot 2)\end{array}$ & $\begin{array}{l}\text { NS } \\
\text { NS }\end{array}$ & $\begin{array}{l}\text { NS } \\
\text { NS }\end{array}$ \\
\hline $\begin{array}{l}\text { PT flex } \\
\text { PT ext } \\
\text { Finger Tapping } \\
\text { Nine hole peg test }\end{array}$ & $\begin{array}{l}5 \cdot 3(4 \cdot 5) \\
3 \cdot 7(2 \cdot 4) \\
38 \cdot 9(10 \cdot 4) \\
29 \cdot 8(6 \cdot 4)\end{array}$ & $\begin{array}{r}9 \cdot 1(5 \cdot 2) \\
6 \cdot 1(3 \cdot 5) \\
41 \cdot 6(7 \cdot 8) \\
23 \cdot 4(3 \cdot 7)\end{array}$ & $\begin{array}{l}0.01 \\
0.01 \\
\text { NS } \\
0.001\end{array}$ & $\begin{array}{l}9(3 \cdot 8) \\
6 \cdot 6(2 \cdot 5) \\
38 \cdot 4(7 \cdot 9) \\
18 \cdot 3(3)\end{array}$ & $\begin{array}{l}0.05 \\
0.01 \\
\text { NS } \\
0.001\end{array}$ & $\begin{array}{l}\text { NS } \\
\text { NS } \\
\text { NS } \\
0 \cdot 01\end{array}$ \\
\hline
\end{tabular}

Flex = flexion; ext $=$ extension; inv = inversion; ever = eversion; $\mathrm{C}=$ controls 
would be very surprising if bed rest interferes with the nine hole peg test, hand grip, and isokinetic movements of the wrist. In the same way, it seems that our data do not correspond to the consequences of controlateral axial deficit. In fact, isokinetic tests were performed in a standardised position. Segments not involved in the measurements were fastened by straps. Moreover, even if controlateral deficit can explain proximal deficit, it is an unlikely explanation for distal impairment of the ankle and wrist.

It is justified, as we chose a population of patients with right hemiplegia, to ask if this deficit could be related to apraxic symptoms. Apraxia is defined as a disorder of learned movement not caused by weakness, akinesia, deafferentation, abnormality of tone, posture, abnormal movement such as tremors and chorea, intellectual deterioration, poor comprehension, or lack of cooperation. ${ }^{23}$ Some authors have recorded up to $50 \%$ of right hemiplegic patients with apraxic disorders. ${ }^{24}$ The presence in our study of a deficit of motor execution (force) prevents validation of any apraxia. Moreover, as a left sided motor deficit exists, perhaps apraxic symptoms currently detected by practioners when they test the motor function of the supposed healthy side of right hemiplegic patients are not really related to apraxia and apraxia is sometimes overdiagnosed.

Ipsilateral motor deficits have already been reported in patients with hemispheric lesions affecting skilled sensory-motor tasks such as the pegboard task. ${ }^{25}$ Conflicting results appeared concerning finger tapping and grip strength. ${ }^{26-28}$ Some authors found a significant impairment ${ }^{2628}$ which was not recorded by others. ${ }^{27}$

Colebatch and Gandevia measured the moment created by an isometric effort in a population of 20 hemiplegic patients at different times after their stroke. ${ }^{4}$ They also found an impairment of the supposed healthy side. The deficit prevailed on shoulder abduction and wrist extension ${ }^{4}$ and the lower limb was globally affected. ${ }^{3}$

Concurrently, Jones et $a l^{2}$ found in a population of eight hemiplegic patients an impairment of handgrip and of shoulder motor function of the healthy side. This deficit recovered within the first month. They also recorded an impairment of visuomotor coordination of the healthy side.

Hence at least three different studies, using different protocols and populations, found an impairment in motor performance of the supposed healthy side after stroke. This is in agreement with our findings. Nevertheless, we underline that the deficit we showed affected both distal and proximal parts of each limb. This suggests that the bilateral input of motor function does not focus exclusively on the proximal segments of each limb but also participates in the motor control of the distal parts. Moreover, to our knowledge, our study is the first to measure phasic strength during the performance of movement. Finger tapping is the only test which failed to detect any deficit. Finger tapping measures rapid, simple, and repetitive movements and does not test force. Our data suggest that left sided motor deficit concerned mainly force (hand grip, isokinetic testing) and dexterity (nine hole peg test) but spared rapid repetitive movements. This implies that ipsilateral automatic motor function and its corticosubcortical loops were not affected in our patients.

The evidence of a motor deficit affecting the supposedly healthy side of patients with right hemiplegia raises the question of the existence of ipsilateral motor pathways. Several arguments exist in the medical literature to support this hypothesis. Activation studies with PET and more recently fMRI support the participation of ipsilateral motor pathways in the motor function of normal subjects and of patients. Several PET or SPECT studies in normal subjects ${ }^{529}$ showed no significant activation of ipsilateral motor cortices during the performance of a standardised motor task despite a trend in some. ${ }^{5}$ Nevertheless, recent studies with more subjects showed that the complexity of the task was correlated with a discrete but real activation of the ipsilateral cortices. ${ }^{6} \mathrm{We}$ personally found, using fMRI (Siemens Vision $1.5 \mathrm{~T}$ ), that in normal subjects the performance of a unilateral motor task resulted in a bilateral activation of motor areas (unpublished data). Activation of ipsilateral motor cortices has been shown many times in patients with acute neurological disease. ${ }^{7-9} 30$ Ipsilateral motor cortices are activated in patients with recovered vascular hemiplegia during the performance of a motor task and they may play a part in functional reorganisation processes.

In 10 patients recovering from stroke, Palmer et $a l^{31}$ using electromagnetic stimulations of the unaffected hemisphere, failed to show that in adults, recovery from stroke resulted from the emergence of ipsilateral fast conducting corticospinal pathways. They showed that stimuli sufficient to excite the neurons of the fast conducting corticospinal pathway (short latency facilitation of contralateral biceps motor neurons) did not produce short latency depolarisation of motor neurons of the ipsilateral biceps.

The study of patients with mirror movements and with hemispherectomy ${ }^{32-34}$ provides us with some more arguments in favour of an oligosynaptic pathway.

Carr et $a l^{32}$ found evidence for reorganisation of central motor pathways in 21 of 33 patients with hemiplegic cerebral palsy. The clinical and neurophysiological findings disclosed two different forms of reorganisation according to the intensity of the mirror movements and to the onset of the motor deficit in life. Some patients with congenital hemiplegia had intense mirror movements and evidence for bilateral fast conducting corticospinal pathways. Other patients with an acquired hemiplegia between 9 months and 7 years of age had weaker mirror movement. Magnetic stimulation of the healthy hemisphere induced the usual controlateral answer but also induced an ispsilateral evoked potential which 
occurred $4 \mathrm{~ms}$ later on average than the contralateral one. This ipsilateral answer was also smaller than the contralateral one. These results suggest that in this group another mechanism for mirror movement could be identified which could implicate an oligosynaptic ipsilateral motor pathway even after maturation of the corticospinal tract. This pathway might participate in the recovery processes of acquired hemiplegia.

In a population of patients with hemispherectomy, Benecke et $a l^{33}$ found comparable results. The magnetic stimulation of the unaffected hemisphere provided both ipsilateral and controlateral potentials. The amplitudes of ipsilateral compound muscle action potentials roughly correlated with their individual residual motor capacities and showed a proximal-distal gradient. In patients with early brain damage the ipsilateral potential had short latencies and large amplitudes, whereas patients with later acquired brain damage presented long latencies and small amplitude.

Comparable results were found in patients with a degenerated pyramidal tract. ${ }^{35}$

Overall, these reports suggest that the reinforcement of the ipsilateral motor pathways may play a dominant part in the ipsilateral motor control of patients with brain damage. The efficiency of this control seems to be greater when the lesion occurs early in life. Our results provide some arguments to suggest that this ipsilateral motor control also exists at the beginning of the stroke even in the adult population.

A fuller characterisation of ipsilateral motor pathways remains to be achieved. Two main hypotheses need to be tested. A transcallosal inhibitory pathway disrupted on hemispheric lesion has been proposed by some authors. A twice crossed spinal tract was proposed by others. ${ }^{33-37}$

We suggest that ipsilateral deficit must be taken into account in the rehabilitation procedures. This aspect needs to be tested precisely.

1 Brodal A. Self observation and neuro-anatomical considerations after a stroke. Brain 1973;96;675-94.

2 Jones RJ, Donaldson IM, Parkin PJ. Impairment and recovery of ipsilateral sensory-motor function following unilateral cerebral infarction. Brain 1989;112:113-32.

3 Adams RW, Gandevia SC, Skuse NF. The distribution of muscular weakness in upper motor neuron lesions affecting the lower limb. Brain 1990;113:1459-76.

4 Colebatch JG, Gandevia SC. The distribution of muscular weakness in upper motor neuron lesions affecting the arm. Brain 1989;112:749-63.

5 Sabatini U, Chollet F, Rascol O, et al. Effect of side and rate of stimulation on cerebral blood flow changes in motor areas during finger movements in humans. $f$ Cereb motor areas during finger movements

6 Shibasaki H, Sadato N, Lyshkow H, et al. Both primary motor cortex and supplementary motor area play a role in complex finger movement. Brain 1993;116:1387-98.

7 Chollet F, Di Piero V, Wise RJS, Brooks DJ, Dolan RJ, Frackowiak RSJ. The functional anatomy of moto recovery after stroke in humans: a study with positron emission tomography. Ann Neurol 1991:29;63-71.

8 Weiller C, Chollet F, Friston KJ, Wise RJS, Frackowiak RSJ. Functional reorganisation of the brain in recovery from striatocapsular infarction in man. Ann Neurol 1992;315:463-72.

9 Chollet F, Weiller C. Imaging recovery of function following brain injury. Curr Opin Neurobiol 1994;42:226-30.

10 Wade DT. Measurement in neurological rehabilitation. London: Oxford medicine, 1992.

11 Sheik K, Smith D, Meade T, Brennan P, Ide L. Assessement of motor function in studies of chronic disability. Rheumatologic Disease 1980;19:83-90.

12 Lee K, Carson L, Kinnin E, Paterson V. The Asworth scale: a reliable and reproductible method of measuring spasticity. Fournal of Neurological Rehabilitation 1989;3: 205-9.

13 Demeurisse G, Demol O, Robay E. Motor evaluation in vascular hemiplegia. Eur Neurol 1980;19:382-9.

14 Spreen O, Strauss EE. A compendium of neuropsychological tests: administration, norms, and commentary. London: Oxford Medicine, 1991 .

15 Bornstein RA. Normative data on selected neuropsychological measures from a nonclinical sample. $f$ Clin Psychol 1985;41:651-59.

16 Thortensson A. Dynamic dynamometry-biomechanical and neuromucular principles. Scand $\mathcal{F}$ Rehabil Med Suppl $276 ; 1992$.

17 Knapik J, Marcos U. Isokinetic and isometric torque relationship in the human body. Arch Phys Med Rehabil 1980;60:64-7.

18 Winter DA, Wells RP, Orr GW. Errors in the use of isokinetic dynamometers. Eur f Appl Physiol 1981;46: 397-408.

19 Frontera WR, Hughes VA, Dallal GE, Evans WJ. Reliability of isokinetic muscle strength testing in 45- to 75-year-old men and women. Arch Phys Med Rehabil 75-year-old men

20 Lyngberg K, Danneskiold-Samsoe B, Ramsing BU. Isokinetic knee extension training in rheumatoid arthritis. Scand $\mathcal{F}$ Rehabil Med 1992;24(suppl 27):29-30.

21 Knutsson E. Concentric and eccentric muscle work in spastic paresis. Scand $\mathcal{f}$ Rehabil Med 1992;24(suppl 27): 16-17.

22 Davies GJ A. Compendium of isokinetics in clinical usage and rehabilitation techniques. 4th ed. Wisconsin: SS Publishers, 1992.

23 De Renzi E, Faglioni P, Sorgato P. Modality-specific and supramodal mechanisms of apraxia. Brain 1982;102: 301-12.

24 De Renzi E, Motti F, Nichelli P. Imitating gesture. A quantitative approach to ideomotor apraxia. Arch Neurol 1980;37:6-10.

25 Vaughan HG, Costa LD. Performance of patients with lateralized cerebral lesions. II. Sensory and motor tests. $\mathcal{F}$ Nerv Ment Dis 1962;134:237-43.

26 Wyke $M$. The effects of brain lesions on the performance of bilateral arm movements. Neuropsychologia 1971;9:33-42.

27 Haaland KY, Delaney HD. Motor deficits after left or right hemisphere damage due to stroke or tumor. Neuropsychologia 1981;19:17-27.

28 Finlayson MAJ, Reitan RM. Effect of lateralized lesions on ipsilateral and controlateral motor functioning. $f$ Clin Neuropsychol 1980;2:237-43.

29 Roland PE, Meyer E, Shibasaki T. Regional cerebral blood flow changes in cortex and basal ganglia during voluntary movements in normal humans volunteers. $\mathcal{f}$ Neurophysiol 1982;48:467-80.

$30 \mathrm{Di}$ Piero V, Chollet F, MacCarthy P, Lenzi GL, Frackowiak RSJ. Motor recovery after acute ischaemic stroke: a metabolic study. $\mathcal{F}$ Neurol Neurosurg Psychiatry 1992;55:990-6

31 Palmer E, Ashby P, Hajek VE. Ipsilateral fast cortisospinal pathways do not account for recovery in stroke. Ann Neurol 1992;2:519-25.

32 Carr LJ, Harrison LM, Evanns AL, Stephens, JA. Pattern of central motor reorganization in hemiplegic cerebral palsy. Brain 1993;116:1223-47.

33 Benecke R, Meyer BU, Freund HJ. Reorganisation of descending motor pathways in patients after hemispherectomy and severe hemispheric lesions demonstrated by magnetic brain stimulation. Exp Brain Res 1991;83:419-26.

34 Cohen LG, Meer J, Tarkka I. Congenital mirror movements: abnormal organization of motor pathways in two patients. Brain 1991;114:381-403.

35 Fries W, Danek A, Thomas NW. Motor responses after transcranial electrical stimuation of cerebral hemispheres with a degenerated pyramidal tract. Ann Neurol 1991; 29:646-50.

36 Pierrrot-Deseilligny E. Le système propiospinal C3-C4: exemple d'intégration dans le système moteur et voie possible pour la récupération motrice. Rev Neurol (Paris) 1994;150:327-9.

37 Wassermann EM, Fuhr P, Leonardo G, Cohen L, Hallet $M$. Effects of transcranial magnetic stimulation on ipsilateral muscles. Neurology 1991;41:1795-9. 